\title{
A Study on Pattern of Heart Disease and Maternal and Fetal Outcome of Pregnancy in a Tertiary Level Hospital
}

\author{
NAHREEN AKHTAR ${ }^{1}$, TAJMIRA SULTANA ${ }^{1}$, SYEDA SAYEEDA ${ }^{2}$, TABASSUM PARVEEN $^{1}$,FIROZA BEGUM $^{1}$
}

${ }^{1}$ Fetomaternal Medicine Wing, Dept of Obs \& Gynae, Bangabandhu Sheikh Mujib Medical University, Dhaka, ${ }^{2}$ Dept of Obs \& Gynae, Bangabandhu Sheikh Mujib Medical University, Dhaka.

Address for Correspondence: Dr Nahreen Akhtar Professor, Fetomaternal Medicine wing, Department of Obstetric \& Gynaecology. Bangabandhu Sheikh Mujib Medical University, Dhaka. E-mail - nahreenakhtar10@g mail.com

\begin{abstract}
:
Background: Cardiac disease is the most common cause of indirect maternal deaths and the most common cause of death overall. It complicates 1\% of maternal death. Objective: Management of pregnancy in patients with valvular heart disease continues to pose a challenge to the clinician.the present study was therefore design to find the pattern of Heart Disease and to evaluate the maternal and fetal outcome of pregnancy. Method: This is a cross sectional study done during the period Jan to Dec, 2011in fetomaternal medicine wing of department of Obs \& Gynae, BSMMU. All the patients admitted with heart disease in pregnancy during this study period were included in this study. This study prospectively enrolled 54 pregnant women with heart disease.All cases were followed during pregnancy, labour, delivery and in early puerperium. Results: The mean (SD \pm ) age of the patients was $26.08 \pm 3.96$ ranging from 20 to 35yrs, most ( $26 \%$ ) belonged to age group 26 - 30yrs and five (9.26\%) belonged to >30years of age group. Most of the patients 21 (38.89\%) were primigravid and $16(29.63 \%)$ patients were of second gravida. Out of 54 patients $41(75.93 \%)$ women received regular antenatal checkup.Thirty eight(70.37\%) patients suffered from rheumatic heart disease. Twenty patients had single valvular involvement, either mitral, tricuspid or pulmonary valve with or without complication. Most of the patients had $\mathrm{EF}>50 \%$ and two patients had $\mathrm{EF}<49 \%$. Two patients had mild mitral stenosis $\left(>1.5 \mathrm{~cm}^{2}\right), 5$ patients had moderate mitral stenosis $\left(1-1.5 \mathrm{~cm}^{2}\right)$ and 6 patients had severe mitral stenosis $\left(<1 \mathrm{~cm}^{2}\right)$. Conclusion: Patients with heart disease should be meticulously managed preconceptionally up to the postpartum period by maternal-fetal medicine specialists, obstetricians, cardiologists, and anesthesiologists using a multi-disciplinary approach to their cardiac conditions to have a better outcome of mother and baby.
\end{abstract}

Key words: Heart disease, pregnancy

Introduction:

Pregnancy makes a significant demand on the cardiovascular system. Therefore, it follows that women with cardiovascular compromise due to cardiac disease need specialist input and careful management of pre-, peri, and post-partum. In the latest CEMACH (Confidential inquiry into maternal and Child health) report in UK , cardiac disease was the most common cause of indirect maternal deaths and the most common cause of death overall. ${ }^{1}$ It complicates $1 \%$ of maternal death. ${ }^{1}$ In particular, during 2003-5, there was an increase in deaths due to myocardial infarction, thoracic aortic dissection, and rheumatic mitral stenosis. ${ }^{1}$ The incidence of cardiac disease during pregnancy has remained stable for many years since the significant decrease in the occurrence of rheumatic heart disease in the last $40 \mathrm{yrs}$ has been compensated by a significant increase of pregnancy in women with congenital heart disease. In developed countries survival of newborns affected by congenital heart disease is about $85 \%$ - in many cases as a result of complex surgical procedures performed in the first few months of life. ${ }^{1}$ Women with heart disease who desire or anticipate pregnancy should have preconceptional councelling. ${ }^{2}$ Most women with heart disease have successful pregnancies, but complacency in the diagnosis and management of pregnant patients can have dire consequences for both the mother and the fetus. ${ }^{3}$ Discussion of clinical problems that women may develop during pregnancy is an important part. Therefore it is essential to evaluate every pregnant woman with heart disease for her risk of adverse outcomes during pregnancy, labour, delivery and postpartum. Ideally patients with heart disease should consult their physicians prior to their becoming pregnant. Preconceptional councelling allows for optimal conception, completion of all diagnostic procedures beforehand, discontinuation of teratogenic 
drugs and scheduling of corrective/palliative surgery before pregnancy. ${ }^{3}$ Heart disease is the most common cause of maternal death in the UK. ${ }^{4}$ The most common cardiac causes of death involve cardiomyopathy and pulmonary hypertension. Rheumatic mitral stenosis is the most common clinically significant valvular abnormality in pregnant women and may be associated with pulmonary congestion, edema, and atrial arrhythmias during pregnancy or soon after delivery. The increased volume load and increased cardiac output associated with pregnancy lead to an increase in left atrial volume and pressure,

elevated pulmonary venous filling pressures, dyspnea, and decreased exercise tolerance. Increases in the maternal heart rate decrease the diastolic filling period, further increasing left atrial pressure. Mortality among pregnant women with minimal symptoms is less than 1 percent. ${ }^{5}$ In a study of women with mitral stenosis, predictors of adverse maternal outcomes included a reduced mitral-valve area (less than $1.5 \mathrm{~cm}^{2}$ ) and an abnormal functional class before pregnancy. ${ }^{5}$ Fetal mortality increases with deteriorating maternal functional capacity; fetal mortality is 30 percent when there is NYHA class IV disease in the mother. 5

\section{Materials \& Methods:}

This observational study was carried out from January 2011 to December 2011 in fetomaternal unit in the department of Obstetrics \& Gynaecology, BSMMU. All pregnant women with congenital or acquired cardiac lesion were eligible for enrollement. This study prospectively enrolled 54 pregnant women with heart disease receiving care in fetomaternal OPD or outside this hospital. Baseline data recorded include patients age, gestational age, New York Heart Association (NYHA) functional class, parity status, comorbid conditions, prior cardiac events, cardiac lesion,prior surgical interventions, cyanosis, oxygen saturation, medications used, ECG, echocardiography, Doppler quantification of inflow or outflow obstruction, valvular regurgitation and systolic pulmonary artery pressure. After admission grading of heart disease was done according to the criteria of New York Heart Association (NYHA) functional classification. All patients were evaluated by obstetrician and cardiologists and also to anaesthesiologists, those patient who needed elective caesarean section. Gestational age were calculated from last menstrual period, clinical examination and from early ultrasonography. Fetal condition were assessed clinically and by ultrasonography, biophysical profile and cardiotocography where needed.The mode of delivery was decided on the basis of maternal and fetal condition.Those patients who went into labour spontaneously were allowed vaginal delivery if there were no contraindication. Most cases delivered by cesarean section considering maternal and fetal condition. All the neonates were examined by neonatologists. All the information was gathered in a prepared data sheet.

\section{Results:}

The mean ( $\mathrm{SD} \pm$ ) age of the patients was $26.08 \pm 3.96$ ranging from 20 to 35yrs, most ( $26 \%$ ) belonged to age group 26 - 30yrs and five (9.26\% ) belonged to > 30years of age group. Regarding parity and gravida, most of the patients 21 (38.89\%) were primigravid and 16 (29.63\% ) patients were of second gravida. Out of 54 patients 41(75.93\%) women received regular antenatal checkup. (Table-1) Thirty eight (70.37\%) patients suffered from rheumatic heart disease. Twenty patients had single valvular involvement, either mitral, tricuspid or pulmonary valve with or without complication. Twenty two patients had two valve involvement and two patients had multiple valvular involvement. Most of the patients had EF >50\% and two patients had EF $<49 \%$. Two patients had mild mitral stenosis $\left(>1.5 \mathrm{~cm}^{2}\right), 5$ patients had moderate mitral stenosis $\left(1-1.5 \mathrm{~cm}^{2}\right)$ and 6 patients had severe mitral stenosis $\left(<1 \mathrm{~cm}^{2}\right)$. Fifteen patients received diuretics for pulmonary congestion, seven patients received â blocker for supraventricular tachycardia, five patients received anticoagulants ( 2 patients for valve replacement),10 patients need digitalisation.

Table-I

Base line characteristics $(N=54)$

\begin{tabular}{lccc}
\hline Parameters & Frequency & Percentage & Mean \\
\hline $\begin{array}{l}\text { Maternal age(years) } \\
\text { 20-25 }\end{array}$ & 23 & 42.59 & \\
$26-30$ & 26 & 48.15 & $26.08 \pm 3.96$ \\
$\quad>30$ & 05 & 09.26 & \\
Gravida & & & \\
1 & 16 & 29.63 & \\
2 & 13 & 24.07 & \\
3 & 16 & 29.63 & \\
4 or more & 09 & 16.67 & \\
Antenatal care & & & \\
Regular & 41 & & \\
Irregular & 13 & & \\
\hline
\end{tabular}

Table I shows mean (SD \pm ) age of the patients was $26.08 \pm 3.96$, most ( $26 \%$ ) belonged to age group 26 - 30yrs and five $(9.26 \%$ ) belonged to $>30 y e a r s$ of age group. Regarding gravida, 16(29.63\% ) patients were primigravida. 41(75.93\%) women received regular antenatal check up. 
Fig . 1: shows that most, thirty eight (70.37\%) patients suffered from rheumatic heart disease. Twenty patients had single valvular involvement, either mitral, tricuspid or pulmonary valve with or without complication. Twenty two patients had two valve involvement and two patients had multiple valvular involvement. N.B multiple vulvular involvement is common than single. Here overlapping are shown in a diagrammatic figure.

Fig 2 shows most of the patient had isolated ASD (11.11\%) among congenital heart disease

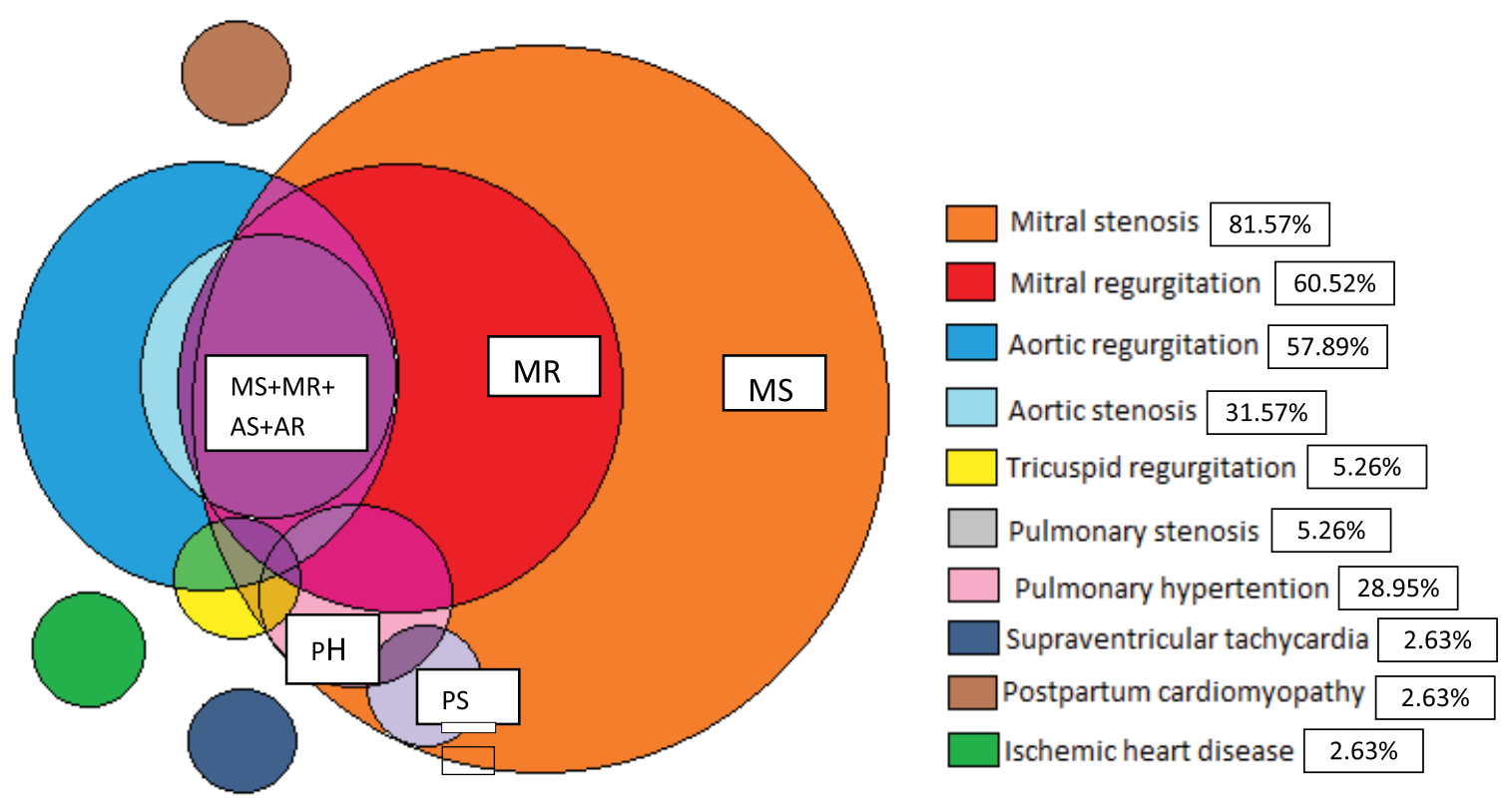

Fig .-1: Type of heart disease $(N=54)$

1. Acquired Heart Disease $\left(n_{1}=38\right)$
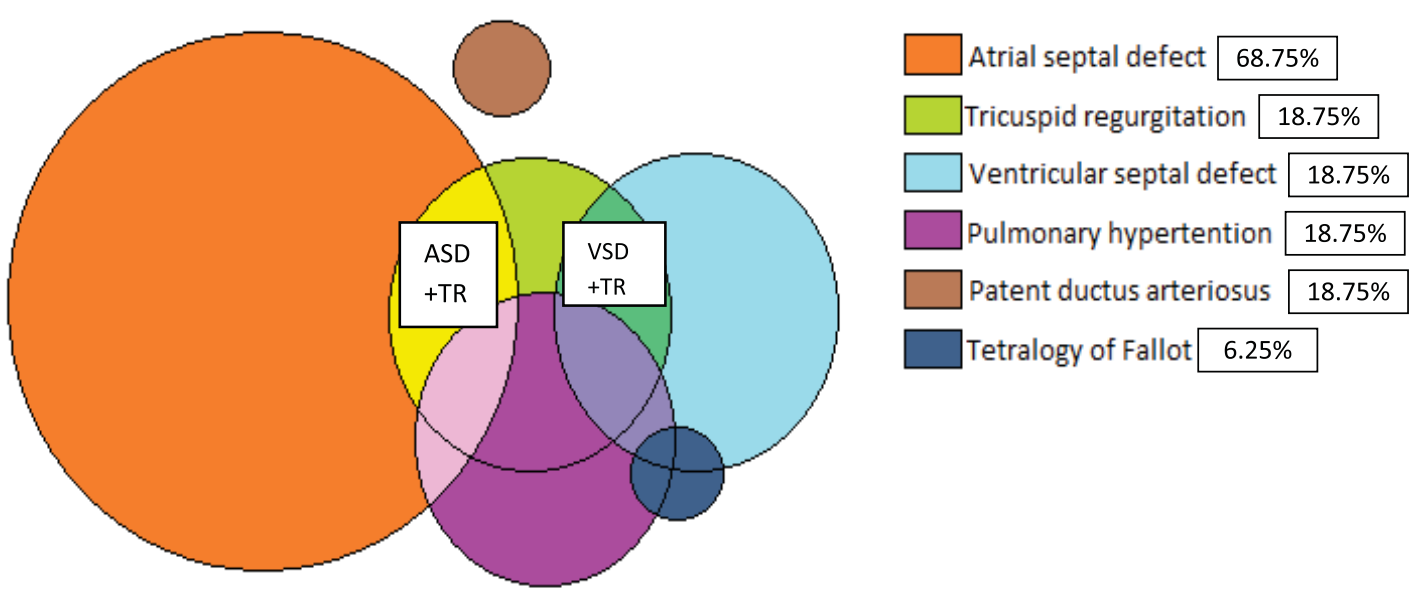

Fig.-2: Congenital Heart Disease $\left(n_{2}=16\right)$ 
Table- II

History of Cardiac surgery prior to pregnancy $(N-54)$

\begin{tabular}{lcc}
\hline $\begin{array}{l}\text { History of Cardiac } \\
\text { surgery }\end{array}$ & $\begin{array}{c}\text { Number of } \\
\text { patients }\end{array}$ & Percentage \\
\hline Present & 24 & 44.44 \\
Absent & 30 & 55.56 \\
\hline
\end{tabular}

Of 54 women only 24(44.44\%) patients had cardiac surgery before pregnancy.

Table-III

Type of cardiac surgery $(n=24)$

\begin{tabular}{lc}
\hline Type & Number \\
\hline ASD repair & 03 \\
PTMC & 09 \\
CMC & 01 \\
CMC +failed PTMC & 01 \\
Cardiac Catheterisation & 02 \\
Mitral valve replacement & 01 \\
Aortic valve replacement & 02 \\
Ventriculo septal defect repair & 01 \\
Vulvuloplasty & 01 \\
Balloon surgery & 01 \\
TOF correction & 01 \\
Partial anomalous pulmonary venous & 01 \\
circulation & \\
\hline
\end{tabular}

Table-III shows nine patients undergo PTMC operation for mitral stenosis. Three patients had repair of ASD .

\section{Table-IV}

Distribution of patients ( $N$-54) according to NYHA classification

\begin{tabular}{lcc}
\hline NYHA class & No of pt. & percentage \\
\hline Grade I & 41 & 87.04 \\
Grade II & 10 & 7.41 \\
Grade III & 03 & 5.56 \\
Grade IV & 00 & 00 \\
\hline
\end{tabular}

Most of the patients (87.04\%) were of grade I heart disease. None of the patients were of grade IV heart disease.

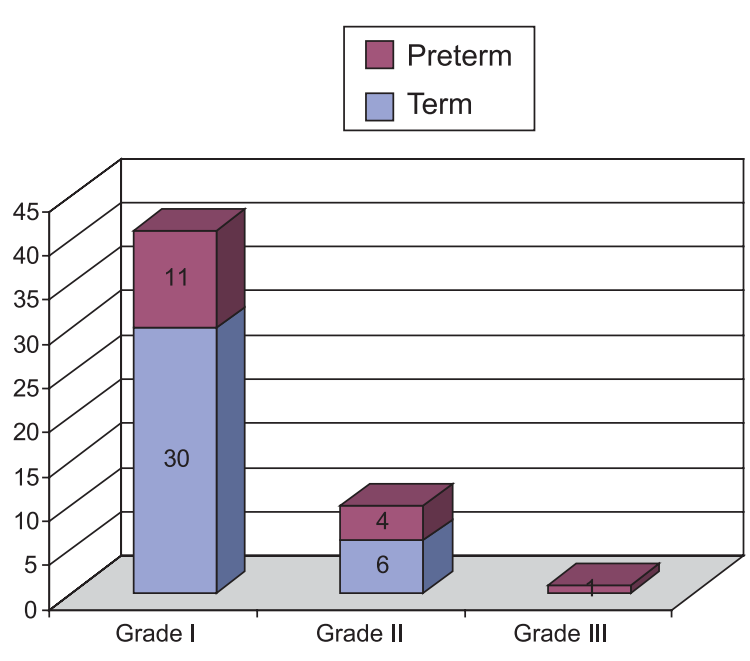

Fig.-3: Gestational age at delivery according to grading $N-52$

Most patients of grade I (62.96\%) delivered at term > 37wks.

Table-V

Gestational age at deliveries (N-52)

\begin{tabular}{lccc}
\hline & $\begin{array}{c}\text { Total } \\
\text { deliveries }\end{array}$ & Term & Preterm \\
\hline Congenital Heart disease & 14 & 09 & 07 \\
Rheumatic Heart disease & 36 & 26 & 10 \\
Others & 02 & 02 & \\
\hline
\end{tabular}

Most of the patients with rheumatic heart disease (36) were delivered at term.

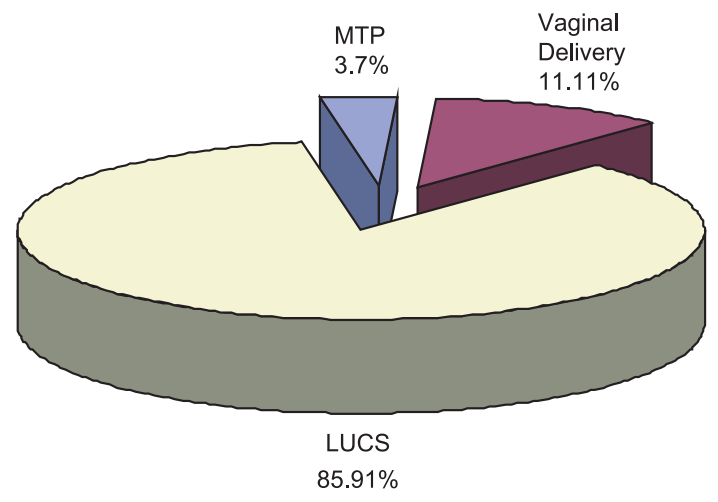

Fig. -4: Distribution of patients ( $N$ - 54) according to mode of delivery.

Fig IV: shows most of the respondents (85.19\%) had delivered by LUCS.2 patients need medical termination. 1 patient had $2^{0}$ ASD with severe pulmonary hypertension and other patient had large VSD with TR with severe pulmonary hypertension. 
Table-VI

Fetal outcome (n-52)

\begin{tabular}{lccc}
\hline $\begin{array}{l}\text { Functional } \\
\text { Classification }\end{array}$ & $\begin{array}{c}\text { Term } \\
\text { Delivery }\end{array}$ & $\begin{array}{c}\text { Preterm } \\
\text { Delivery }\end{array}$ & $\begin{array}{c}\text { Birth } \\
\text { weight Kg }\end{array}$ \\
\hline Grade I $(n=47)$ & 30 & 11 & $2.5 \pm 0.3$ \\
GradeII $(n=10)$ & 06 & 04 & $2.4 \pm 0.2$ \\
GradeIII $(n=03)$ & 00 & 01 & 2.4 \\
\hline
\end{tabular}

Table VI shows 30 patient of Grade I disease had term delivery and 6 patients of grade II had term delivery.Mean birth weight in grade I heart disease was $2.5 \pm 0.3 \mathrm{~kg}$.

Discussion: During the present study period of of $1 \mathrm{yr}$ time, there were 1054 deliveries with fifty four case of parturients complicated with heart disease. So the prevalence of parturients complicated with heart disease is $5.12 \%$. Among them 38 (70.37\%) patients had rheumatic heart disease and mitral stenosis was the most common lesion 5(9.26\%). The rest, 16 (29.63\%) had congenital lesion of which atrial septal defect was the most common form 6 (11.11\%). In developed countries, a few decades before, rheumatic heart disease was the most common in pregnant women ${ }^{6,7}$ and now a days it is still the most common heart disease in some developing countries. ${ }^{8}$ However recently it is the same trend around the world that the most common heart disease in parturients is congenital. ${ }^{9}$ In one study in Rajvithi Hospital, Thailand congenital heart disease was the most common type of heart disease, its prevalence was slightly more than that of the rheumatic heart disease (49.4\% : 44.9\%). ${ }^{10}$ The reason behind this, was increasingly performed cardiac surgery in congenital heart disease in young women. In one study by Jatavan showed Rheumatic heart disease was more common than congenital heart disease (48.8\% \& 44\%). ${ }^{11}$ A study by Karaalp ${ }^{12}$ showed majority of the patients with heart disease in pregnancy had rheumatic heart disease (70\%) and most of heart lesions were mitral stenosis and atrial septal defect was the most common congenital heart lesion.This finding is similar to this study. Table I shows the baseline characteristics of parturient. Mean maternal age was $26.08 \pm 3.96$, primigravid was $38.89 \%$ and $75.93 \%$ patients took regular antenatal care. Some of this findings are consistent with the study by Sawhney et al. also found mean $( \pm S D)$ maternal age was $27( \pm 4)$ years and primigravida 53 percent. ${ }^{13}$ A study done by Hameed, showed mean maternal age was $29 \pm 7$ and 48 out of 66 was multiparous. ${ }^{14}$ Table II shows rheumatic heart disease present in more than two third of patients. Pulmonary congestion was the most frequent complication in patient with mitral stenosis, not withstanding all of them were in NYHA functional class I/II at the beginning of pregnancy. This functional classI/II does not assure an uneventful pregnancy in mitral stenosis. In these cases, the use of furosemide and propranolol allowed clinical control in most patients upto delivery, a fact that favours medical therapy as the first option for management. Table III shows most of patients 30(55.56\%) had no H/O cardiac surgery prior to pregnancy. Twenty four patients (44.44\%) had H/O cardiac surgery and 9 patient had H/O PTMC for mitral stenosis (Table III). In one study by Kovavisarach ${ }^{10}$ showed 70(35.7\%) had corrected heart disease ${ }^{14}$ which is inconsistent with this study. This may be due to ignorancy, illiteracy and lack of awareness of women in our country. In another study by Samuel who showed $46 \%$ mother had undergone surgical intervention before pregnancy. ${ }^{15}$ Most of the patient (87.04\%) in this study was in grade I according to NYHA classification (Table IV). In one study, ${ }^{10} 166$ (84.7\%) had grade I according to NYHA classification in first antenatal check up and found no patient with grade III and IV. Most of our patients of grade I (62.96\%) delivered at term ( $\geq 37 \mathrm{wks}), 2$ (3.7\%) patient had medical termination. Both patients had congenital heart disease with severe pulmonary hypertension.(Fig III, Table V). In one study 36 (55\%) patients were in functional gd I, 28 ( 42\% ) were in gd II and 2(3\%) in gd III. Forty patients (62\%) showed deterioration of at least one functional class during pregnancy, which occurred diring the first trimester in 8patients, second trimester in 26 patient and third trimester in 6 patients. ${ }^{16}$ In this study operative delivery (LUCS) was most common mode of delivery 46(85.19\%) (Fig IV). However a study by Kovavisarach showed $44.9 \%$ had vaginal delivery. ${ }^{10} \mathrm{~A}$ study by Walkiria showed vaginal delivery in 613(65\%) patients and had cesarean section in 331(35\%), mostly for obstetric indication like IUGR, fetal distress and labour induction failure. ${ }^{17}$ In this study 3.7\% patients had therapeutic abortion. Both of them had congenital heart disease with severe pulmonary hypertension. In one study, they showed $5 \%$ had therapeutic abortion. ${ }^{14}$ This study shows mean birth weight of baby were $2.5 \pm 0.3 \mathrm{~kg}$ of term pregnancy. There were no maternal or fetal death. One study showed that prematurity, low birth weight, fetal growth restriction, birth asphyxia is more in cases than control. ${ }^{11}$

\section{Conclusion:}

Pre-pregnancy counselling should be offered to all women with heart disease to prevent avoidable pregnancy-related risks and crisis management and allow patients to plan their lives. Successful pregnancy is feasible for most women with congenital heart disease at relatively low risk 
when appropriate counselling and optimal care are provided. For patients with valvular disease,careful clinical assessment and echocardiography are warranted before conception, in order to assess functional capacity and to detect any left ventricular dysfunction or valvular dysfunction. If the patient has abnormal functional capacity, left ventricular dysfunction, valve obstruction, or a history of heart failure or embolic events, she should be counseled regarding the risk of adverse cardiac outcomes. In patients with more than one such risk factor, pregnancy may not be advisable. A patient who becomes pregnant should be seen by a cardiologist once each trimester and more often if complications ensue. Women with heart disease of pregnancy especially valvular heart disease had good maternal outcome, when heart disease is gd I and II and EF is $>60 \%$. In this group maternal mortality and morbidity is also less.

\section{References:}

1. Lewis G, ed. The Confidential Enquiry into Maternal and Child Health (CEMACH). Saving Mothers' Lives: reviewing maternal deaths to make motherhood safer 2003-2005. The Seventh Report on Confidential Enquiries into Maternal Deaths in the United Kingdom (2007) London: CEMACH.

2. Afshan BH. Cardiac disorders in pregnancy In: Alan HD, Lauren N, Murphy G, Neri L. Current Diagnosis \& Treatment Obstetrics \& Gynecology $10^{\text {th }}$ ed. NewYork: Mc Graw Hill 2003; p359-60

3. Fernando A, Shirish ND, Amarnanth GB. Cardiac Disease and Pregnancy Practical Guide to High Risk Pregnancy \& Delivery $3^{\text {rd }}$ ed. India: Elsevier 2008; 506-7.

4. Royal College of Obstetricians and Gynaecologists. Why mothers die 1997-1999, the confidential enquiries into maternal deaths in the United Kingdom. London: Royal College of Obstetricians Gynaecologist, 2001.

5. Sharon CR, John D. Valvular Heart Disease in Pregnancy. N Engl J Med 2003; 342-52
6. Charoenchob N,Tooguwan S,Suvonnqkote T, Thongtang V, Srivannasoni N. Heart disease with pregnancy in Siriraj Hospital: analysis of 100 cases. J Med Assoc Thai 1982; 65: 543-8

7. Mc Faul PB, Dornan JC, Lamki H, Boyle D. Pregnancy complicated by maternal heart disease. A review of 519 women. Br J Obstet Gynaecol 1988; 95: 861-7

8. Chia P, Raman S, Tham SW. The pregnancy outcome of acyanotic heart disease. J Obstet Gynaecol Res 1998; 24: 267- 73

9. Shime J, Mocarski EJ, Hasting D, Webb GD, Mc Laughlin PR. Congenital heart disease. Am J Obstet Gynecol 1987; 156: 313-22.

10. Kovavisarach E,Nualplot P.Outcome of Pregnancy among Parturients Complicated with Heart Disease in Rajavithi Hospital J Med ssoc Thai 2007;90: 2253-8

11. Jatavan T, Luewan S, Tongsong T. Outcomes of pregnancy complicated by heart disease at Maharaj Nakorn Chiang Mai Hospital. J Med Assoc Thai. 2011;94(10):1159-63.

12. Karaalp S. Effect of valvular heart disease on maternal and fetal outcome in pregnancy. J Am Coll Cardiol 2001; 37: 893-8

13. Sawney H, Aggarwal N, Sury V, Vasisha K, Sharma Y, Grover A. Maternal and perinatal outcome in rheumatic heart disease. Int J Gynaecol Obstet 2003; 80: 9-14.

14. Hameed A, Karaalp IS, Tummala PP, Wani OR, Canetii M et al. Clinical study : valve disease J of the ACOC 2001; 37(3) : 893:99.

15. Samuel CS, Sermer M, Colman JM, Alvarez AN, Mercier LA et al. Prospective multicentre Study of Pregnancy outcomes in women with Heart Disease. Circulation J of American Heart Association 2001; 104: 515-21.

16. Hameed A, Padmini PT, Omar RW, Menahem C, Mohammad WA, Murphy G, Natalia Z, Elkayam U. The effect of valvular heart disease on maternal and fetal outcome of pregnancy $\mathrm{J}$ of the Am Coll of cardiology 2001; 37(3): 893- 99.

17. Avila WS, Rossi ED, Ramires JAF, Grinberg M, Brotolotto MR et al. Pregnancy in patients with heart disease: Experience with 1000 cases. Clin. Cardiol 2003;26:135-42. 